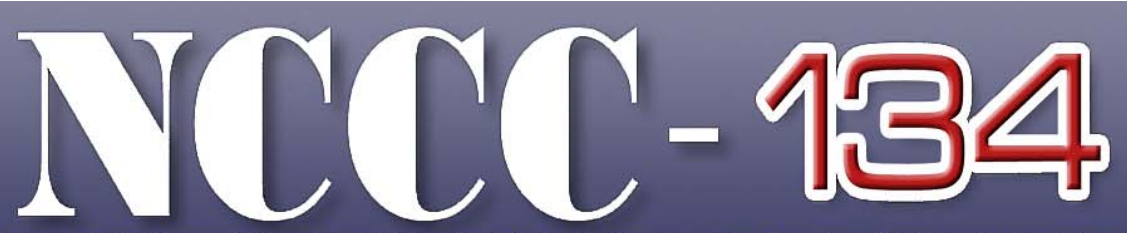

APPLIED COMMODITY PRICE ANALYSIS, FORECASTING AND MARKET RISK MANAGEMENT

\title{
The Marketing Performance of Illinois and Kansas Wheat Farmers
}

by

Sarah N. Dietz, Nicole M. Aulerich, Scott H. Irwin and Darrel L. Good

Suggested citation format:

Dietz, S. N., N. M. Aulerich, S. H. Irwin, D. L. Good. 2008. “The Marketing Performance of Illinois and Kansas Wheat Farmers.” Proceedings of the NCCC-134 Conference on Applied Commodity Price Analysis, Forecasting, and Market Risk Management.

St. Louis, MO. [http://www.farmdoc.uiuc.edu/nccc134]. 


\title{
The Marketing Performance of Illinois and Kansas Wheat Farmers
}

\author{
Sarah N. Dietz \\ Nicole M. Aulerich \\ Scott H. Irwin \\ Darrel L. Good* \\ Paper presented at the NCCC-134 Conference on Applied Commodity Price Analysis, \\ Forecasting, and Market Risk Management, St. Louis, Missouri, \\ April 21-22, 2008
}

Copyright 2008 by Sarah N. Dietz, Nicole M. Aulerich, Scott H. Irwin, and Darrel L. Good. All rights reserved. Readers may make verbatim copies of this document for non-commercial purposes by any means, provided that this copyright notice appears on all such copies

\footnotetext{
* Sarah N. Dietz is a former Graduate Research Assistant for the AgMAS Project in the Department of Agricultural and Consumer Economics at the University of Illinois at Urbana-Champaign. Nicole M. Aulerich is a Graduate Research Assistant for the AgMAS Project in the Department of Agricultural and Consumer Economics at the University of Illinois at Urbana-Champaign. Scott H. Irwin is the Laurence J. Norton Chair of Agricultural Marketing in the Department of Agricultural and Consumer Economics at the University of Illinois at UrbanaChampaign. Darrel L. Good is a Professor in the Department of Agricultural and Consumer Economics at the University of Illinois at Urbana-Champaign. The authors appreciate the research assistance of Evelyn Colino and Ryan Batts. Funding support from the Aurene T. Norton Trust is gratefully acknowledged.
} 


\section{The Marketing Performance of Illinois and Kansas Wheat Farmers}

\section{Practitioner's Abstract}

The purpose of this paper is to investigate the marketing performance of wheat farmers in Illinois and Kansas over 1982-2004. The results show that farmer benchmark prices for wheat in Illinois and Kansas fall in the middle-third of the price range about half to three-quarters of the time. Consistent with previous studies, this refutes the contention that Illinois and Kansas wheat farmers routinely market the bulk of their wheat crop in the bottom portion of the price range. Tests of the average difference between farmer and market benchmark prices are sensitive to the market benchmark considered. Marketing performance of wheat farmers in Illinois and Kansas is about equal to the market if 24- or 20-month market benchmarks are used, is slightly above the market if a 12-month price benchmark is used, and is significantly less than the market if the harvest benchmark is used. The sensitivity of marketing performance to the market benchmark considered is explained by the seasonal pattern of prices. While Illinois producers performed slightly better than their counterparts in Kansas, notable differences in performance across these two geographic areas is not observed.

Key words: benchmarks, Illinois, Kansas, marketing, performance, price, wheat

\section{Introduction}

Since major wheat production began in the United States in the 1870s, wheat farmers have faced "boom and bust" cycles in prices. The behavior of wheat prices presents farmers with a substantial amount of risk, and it is natural for farmers to seek ways of decreasing these risks through improved marketing. Government programs, academic research, and numerous education efforts have been developed to assist in the improvement of marketing performance and management of price risk (Kunze 1990; Allen 1994). Despite these efforts to improve marketing performance, it is still commonly believed that many wheat (and other crop) farmers under-perform in the market. This has led to the oft-repeated adage that, "Farmers market twothirds of their crop in the bottom third of the price range."

The actual marketing performance of crop farmers has been rigorously analyzed in two recent studies. Anderson and Brorsen (2005) study the marketing performance of Oklahoma wheat farmers over 1992-2001 using transactions data from three elevators across the state. Their results show that nearly two-thirds of market transactions are in the top half of the price range for a crop. Average marketing performance of Oklahoma farmers is about equal to or above the market benchmarks considered in the study. Hagedorn et al. (2005) investigate the marketing performance of Illinois farmers in corn and soybeans over 1973-2003 using USDA price received data. They find that performance falls in the middle-third of the price range in most years for both corn and soybeans. Nevertheless, the average marketing performance of Illinois farmers is about $\$ 5$ to $\$ 10 /$ acre below market benchmarks in the majority of comparisons.

Klumpp, Brorsen, and Anderson (2007) hypothesize that the difference in results between the above two studies may be due to data aggregation. Specifically, the underperformance reported by Hagedorn et al. implies that farmers store corn and soybeans too long relative to the storage signals provided by the market. However, this result may reflect a downward bias in Hagedorn 
et al.'s performance measures due to the use of USDA price data that is spatially aggregated (Bernischka and Binkley, 1995; Wright and Williams, 1991). Klumpp, Brorsen, and Anderson compare measures of marketing performance for Oklahoma wheat farmers using elevator transactions data and USDA aggregate price received data and find similar results for both sets of data. The authors conclude that data aggregation does not explain the differences in the two studies.

If data aggregation does not explain the differences in the studies by Anderson and Brorsen and Hagedorn et al., then what does? Klumpp, Brorsen, and Anderson suggest the choice of market benchmark (12-months vs. 24-months) may influence the results. Other possibilities include differences in crops (wheat vs. corn and soybeans), geographic areas (Oklahoma vs. Illinois), and sample periods (1991-2001 vs. 1973-2003). Given the important implications of marketing performance for the overall economic performance of the farm sector and Extension programming, further research is needed to reconcile the conflicting findings in previous studies.

The purpose of this paper is to investigate the marketing performance of wheat farmers in Illinois and Kansas over 1982-2004. The use of two states growing the same crop, winter wheat, provides a test of whether marketing performance is sensitive to differences in production and marketing conditions across geographic areas. Marketing performance of wheat farmers is based on USDA average producer price received data for Illinois and Kansas, which allows the performance tests to be directly comparable to Hagedorn et al. in terms of the source of marketing performance data. The relatively long sample period, 1982-2004, spans a variety of weather and supply and demand conditions and offers the opportunity to test whether marketing performance changes over time. All four of the market benchmarks considered by Anderson and Brorsen and Hagedorn et al. are used in the analysis: 24-, 20-, 12-month and harvest cash price benchmarks. This will provide a more complete test of whether crop marketing performance is sensitive to the market benchmarks considered. Finally, the same market performance tests considered by Anderson and Brorsen and Hagedorn et al. will be used in the analysis.

\section{Computing Farmer Marketing Performance}

Two different geographic locations in Illinois and Kansas were selected in order to attain a crossstate comparison of the marketing performance of wheat farmers. Geographic areas in Illinois and Kansas were selected for two reasons. The first reason is that different types of winter wheat are grown in each state. Illinois produces soft red winter (SRW) wheat while Kansas produces hard red winter (HRW) wheat. The second reason for selecting Illinois and Kansas is due to data availability, in particular, cash and forward price bid data. Specific production regions within these two states were identified for use in the analysis. The West Southwest Crop Reporting District (CRD) of Illinois, highlighted in Panel A of Figure 1, represents one of the largest SRW wheat production regions in Illinois. It ranks third out of nine Illinois CRDs and represents about $20 \%$ of Illinois wheat production. The West Southwest CRD in Illinois is compared to the Southwest CRD of Kansas, highlighted in Panel B of Figure 1. While the Southwest CRD is not the largest wheat production region in Kansas, it is the second largest out of the nine Kansas CRDs and it represents about $17 \%$ of Kansas wheat production. Importantly, the amount of price data readily available for this CRD surpassed any other major production region in Kansas. The two regions in Illinois and Kansas are assumed to represent a "typical" wheat farmer in each state. 
Once geographic regions are specified the process of calculating the marketing performance of farmers is theoretically straightforward: the average price received by a randomly selected, representative sample of grain producers in the geographical area is weighted by actual production amounts during the marketing window. The marketing data should reflect all types of farmer sales, including cash transactions, forward contracts, and the use of futures and options. Unfortunately, such detailed data about individual producer marketing performance is not readily available.

Hagedorn et al. (2005) and Irwin, Good, and Martines-Filho (2006) argue that the average price received series computed by the U.S. Department of Agriculture (USDA) is the best available public data for constructing a measure of farmer marketing performance. The USDA series is based on information collected in monthly mail and telephone surveys of grain dealers, processors and elevators that actively purchase grain from farmers. ${ }^{1}$ The USDA uses a twelvemonth marketing year for measuring wheat sales, June prior to harvest through May after harvest. The average price received estimate for a month is the total value of grain purchased across all surveyed firms divided by total quantities summed across all surveyed firms. This estimate may incorporate statistical adjustments for size differences across reporting firms and other factors. The USDA also tabulates the distribution of farm sales during each marketing year. This distribution, or set of monthly marketing weights, is constructed by dividing the total sales for the twelve-month marketing year by the sales quantity for each month.

The USDA price received series has both strengths and weaknesses with respect to measuring the average price received by farmers. On the positive side, the USDA series reflects the actual pattern of cash grain marketing transactions by farmers, and thus, incorporates the marketing windows and timing strategies actually used by farmers; includes forward contract transactions for both the pre-harvest and post-harvest periods, with the transactions recorded at the forward price, not the spot price at the time of delivery; and grain sales are adjusted to industry standards for moisture. On the negative side, the USDA series is only available in the form of a state average; includes cash transactions for different grades and quality of grain sold by farmers; does not include futures and options trading profits/losses of farmers; and reflects a mix of old and new crop sales by farmers.

Given the measurement issues associated with the USDA average price received series, Hagedorn et al. (2005) and Irwin, Good, and Martines-Filho (2006) compute two alternative farmer benchmarks in their studies of marketing performance. The first is based directly on the USDA average price received series, while the second substitutes spot market prices for average prices received in the computation of the benchmark. In this study, only the second version is used due to the prevalence and variability of quality discounts in wheat. In terms of wheat quality, the major determinants are protein content, test weight, and foreign material. Each of these characteristics is subject to change due to varying geographic regions and growing conditions. For example, the amount of the wheat crop in the Southwest CRD of Kansas that received the standard number one grade ranged from $2 \%$ to $90 \%$ over 1995-2004 (KASS 2004). While comparable data is not available for Illinois, variation in quality is also substantial, if only due to weather.

The first step in computing the farmer benchmark for each state is averaging cash market prices net of physical storage and interest opportunity costs for each month of the 12-month marketing 
year for wheat (June-May). Following Jirik et al. (2000), cash wheat prices in Illinois are collected for the West Southwest Illinois Price Reporting District from the Illinois Department of Ag Market News. This geographic price reporting area most closely reflects the assumed geographic location of a representative wheat farmer in the West Southwest CRD of Illinois. Cash wheat prices for Kansas are collected for specific locations in the Southwest Kansas CRD from the Kansas Department of Ag Market News and a private elevator. In both states, a regional average cash price is computed.

Jirik et al. (2000) and Irwin, Martines-Filho, and Good (2001) surveyed seven elevators in the West Southwest CRD of Illinois to obtain physical storage costs over 1995-1999. Where possible, the same elevators were contacted in 2004 to update storage charge information. Based on this information, Illinois storage charges are assumed to have a fixed component (in-charge) of $4 \mathbb{\$}$ per bushel assigned the day storage begins. A variable component is pro-rated to the date of a sale. Over 1995-1999, the variable component is 2.5\$ per bushel per month, and after 1999, it increases to $3.0 \$$ per bushel per month. No records were maintained by the elevators in Illinois for years prior to 1995. Previous research on commercial storage rates for corn and soybeans in Illinois found that rates changed little from the early 1980s onwards (Hagedorn et al. 2005), therefore it is assumed that commercial storage costs for wheat in Illinois are constant over 19821995.

Physical storage costs in Kansas were collected from four elevators in the Southwest CRD for 1982-2004. In Kansas no fixed component, or in-charge, is assessed. The variable component of the storage charges for 1982-1998 is 2.55 per bushel per month. An increase occurred in 1999 , raising the storage charge to $2.85 \$$ per bushel per month. The relatively constant cost structure over time in Kansas provides support for the assumption that storage costs in Illinois are constant previous to 1995.

Interest opportunity costs for Illinois and Kansas are based on the average rate for all other farm operating loans for the Seventh (Chicago) and the Tenth (Kansas City) Federal Reserve District agricultural banks, respectively, in the third quarter of each year as reported in the Agricultural Finance Databook. Interest rates for the third quarter are assumed to most accurately reflect actual opportunity costs at the end of harvest for a wheat farmer. The interest charge for storing grain is the daily interest rate (assuming daily compounding) times the number of days between the first day after the harvest window until the date of a given sale times the harvest cash price.

After computing average cash market prices net of physical storage and interest opportunity costs for each month, the next step in the calculation of farmer benchmarks is to compute annual weighted-average prices received by multiplying the monthly average (net) cash prices by monthly USDA marketing weights for wheat in each state and marketing year. This assumes that the marketing patterns of farmers in the assumed geographic regions are approximately the same as the average pattern across the respective states. The final step is to add actual state average marketing loan benefits for the 1998-2004 crops. $^{2}$ Benefits from the non-recourse loan program for earlier years are not considered because the price impact of the program was approximately the same for all producers. ${ }^{3}$ Complete details on the computation of the farmer benchmarks can be found in Dietz (2004). 


\section{Market Benchmarks}

Based on efficient market theory, market benchmarks provide a standard of comparison for marketing performance. In its strongest form, efficient market theory predicts that market prices always fully reflect available public and private information (Fama 1970). The practical implication is that no trading strategy can consistently beat the return offered by the market. Hence, the return offered by the market becomes the relevant benchmark. In the context of the present study, a market benchmark should measure the average price offered by the market over the marketing window of Illinois and Kansas wheat farmers. The average price is computed in order to reflect the returns to a naïve, "no-information" strategy of marketing equal amounts of grain each day during the marketing window.

Given the inherent uncertainty about the relevant marketing window for Illinois and Kansas wheat producers, four different market benchmarks are specified. The first is the 24-month market benchmark used in AgMAS performance evaluations of market advisory services (e.g., Irwin, Good, and Martines-Filho 2006). The 24-month market benchmark is computed as the average cash price over a 24-month marketing window that starts in June of the calendar year before harvest and ends in May of the calendar year after harvest. Cash forward contract prices for harvest delivery in southwestern Illinois and Kansas, respectively, are averaged during the pre-harvest period, while spot cash prices for the same geographic areas are averaged during the harvest and post-harvest periods. ${ }^{4}$ A weighted-average price is computed to account for the change from trend yield expectations before harvest to actual yields after harvest. Post-harvest cash prices are adjusted for physical storage and interest opportunity costs following the same assumptions applied to the farmer benchmarks. Marketing loan benefits are added to the benchmark price during the 1998-2004 crop years when positive gains are available.

The other three market benchmarks basically shorten the marketing window of the 24-month benchmark. The 20-month market benchmark is computed by deleting the first four months of the 24-month pricing-window from the computation of the average market price. The 12-month market benchmark averages spot prices (adjusted for physical storage and interest opportunity costs) starting in June of the calendar year of harvest and ends in May of the calendar year after harvest. Finally, the harvest price benchmark averages spot cash prices during the assumed three-week harvest window for each crop year. Complete details on the computation of market benchmarks can be found in Dietz (2004).

\section{Performance Results}

Descriptive statistics on the constructed farmer and market benchmark price series are provided in Table 1. Statistics are presented for both price and revenue per acre. The revenue received series (\$/acre) is constructed by multiplying the farmer benchmark price for each state by the respective actual yield for the year. ${ }^{5}$

The descriptive statistics show that average prices or revenues due not differ markedly, whether farmer benchmarks are compared to the market benchmarks or the four market benchmarks are compared to one another. For example, in Kansas, the average farmer benchmark price over $1982-2004$ is $\$ 2.93 / \mathrm{bu}$. and the market benchmarks range from $\$ 2.90 / \mathrm{bu}$. to $\$ 3.03 / \mathrm{bu}$. In both 
states, the harvest price benchmark has the highest average price over the sample period and the 12-month benchmark has the lowest average price. Average prices are slightly higher in Illinois compared to Kansas. Average revenue is substantially higher in Illinois due to much higher yields per acre.

Variability of prices, as measured by standard deviation, is highest for the harvest price benchmark, due to the small window over which prices are averaged each crop year and lowest for the 24-month benchmark, which incorporates the largest proportion of pre-harvest forward pricing. Variability of the farmer benchmark price tends to be closer to the variability of the harvest price benchmark than the 24-month benchmark. This likely reflects a small amount of pre-harvest pricing by wheat farmers (e.g. NASS 2003 ) and their tendency to concentrate sales near harvest (see Figure 4). While prices are more variable in Kansas than Illinois, the pattern reverses when considering revenue. ${ }^{6}$ This occurs because the price-yield correlation is much larger (in absolute terms) for Kansas than Illinois. For example, the correlation between the harvest price and yield is -0.20 in Illinois and -0.64 in Kansas. This is sensible given the much larger share of winter wheat produced in Kansas.

\section{Price Range Comparisons}

As noted in the introduction, a commonly held and oft-repeated conception of farm marketing performance is that most producers sell the bulk of their crop in the bottom of the price range. Therefore, an evaluation of farmer marketing performance begins with examination of this claim.

The price data used to construct the 24-, 20- and 12-month market benchmarks can be used to estimate each crop year's price range. First, all of the daily prices for each benchmark marketing window and crop year are sorted from high to low. Note that the 24- and 20-month marketing windows include pre-harvest, harvest and post-harvest prices, while the 12-month marketing window includes only harvest and post-harvest prices. As before, all post-harvest prices are adjusted for commercial storage costs (interest and physical storage). Marketing loan benefits are not added to prices for the 1998-2004 crop years because the payments could affect the distribution of prices in those years. Next, percentiles of the price distribution are defined for each crop year. Then, the bottom, middle-, and top-third of the price ranges for each crop year are calculated based on the $0,33^{\text {rd }}, 66^{\text {th }}$ and $100^{\text {th }}$ percentiles of the price distribution. Finally, farmer benchmark prices (without marketing loan payments over 1998-2004) for the same crop year are compared to the price ranges as a measure of marketing performance.

The frequency of farmer benchmark prices falling in the top-, middle- and bottom-third of crop year price ranges over 1982-2004 is presented in Table 2 for Illinois and Kansas. The results show that farmer benchmark prices for wheat in Illinois and Kansas fall in the middle-third of the price range, not the bottom third, about half to three-quarters of the time. Averaged across all three marketing windows, farmer benchmark prices in Illinois fall in the top and bottom third of the price range $23 \%$ and $13 \%$ of the time, respectively. On average, farmer benchmark prices in Kansas fall in the top and bottom third of the price range $12 \%$ and $25 \%$ of the time, respectively. There is no case where the frequency in the bottom-third is even remotely close to the $66 \%$ asserted in the statement that, "Farmers market two-thirds of their crop in the bottom third of the price range.” Therefore, while there is evidence that producer prices received do not always fall 
in the middle or top portion of the year's price range, the results refute the contention that Illinois and Kansas wheat farmers routinely market the bulk of their crop in the bottom portion of the price range.

Two other patterns in the price range results are noteworthy. First, market performance of farmers in both states is best when compared to the 12-month price range. Since the same farmer benchmark price is used to compute the frequencies for the three marketing windows this implies that marketing opportunities are the least favorable during this shorter window. Second, marketing performance of wheat farmers is somewhat better in Illinois than Kansas. Interestingly, this difference is only observed in the top- and bottom-third of the price range.

\section{Average Difference Comparisons}

Evaluating performance relative to price ranges provides an important perspective on the marketing ability of farmers, but it does not provide a formal test of marketing performance. Of particular interest is the average difference between the farmer and market benchmarks.

Table 3 presents statistics on the average difference between the farmer and market benchmarks over 1982-2004 in Illinois and Kansas. Note that a positive difference indicates average farmer performance is above the market benchmark, whereas a negative difference indicates farmer under-performance. A paired $t$-test of zero difference is used to assess the statistical significance of price differences between the two series. ${ }^{7}$ The tests reveal that average difference results are sensitive to the benchmark considered. If the 24- or 20-month price benchmark is selected for comparison, the results show that the marketing performance of wheat farmers in Illinois and Kansas about equals the market. Not surprisingly, average differences versus these two benchmarks are not statistically significant. If the 12-month price benchmark is selected for comparison, results show that wheat farmers in Illinois and Kansas slightly outperform the market. Only the revenue difference for Illinois versus the 12-month benchmark is statistically significant.

If the harvest price benchmark is selected for comparison, results show that wheat farmers in the two states underperform the market, with underperformance averaging \$0.06/bu. in Illinois and $\$ 0.10 /$ bu. in Kansas. Average differences versus the harvest benchmark are statistically significant in all four cases. The magnitude of revenue underperformance versus the harvest price benchmark is about $\$ 3$ to $\$ 4$ /acre. The economic magnitude of underperformance versus the harvest price benchmark certainly is not large compared to the average revenue in each state over the sample period, \$160/acre in Illinois and \$107/acre in Kansas, but it is non-trivial relative to net margins. For example, net returns to labor and management for non-irrigated wheat farms in Kansas averaged only \$28/acre over 1999-2004 (KFMA, 2004).

The sensitivity of performance results to the benchmark considered can be explained by price patterns over the marketing window. This is seen with the aid of Figure 2, which shows average prices (net of physical storage and interest opportunity costs) each month over the 24-month marketing window for wheat in Illinois and Kansas, respectively. In the absence of convenience yields, theory predicts that average prices pre-harvest and average prices post-harvest after adjusting for storage costs should equal the average harvest price. The figures indicate that 
average pre-harvest prices are indeed close to average harvest prices (pre-harvest $+\$ 0.02 / \mathrm{bu}$. in Illinois and $-\$ 0.01 /$ bu. in Kansas). There are two distinct periods in post-harvest prices. Wheat prices (after storage costs) during the first seven months of the post-harvest period, June through December, are, on average, only $\$ 0.05 / \mathrm{bu}$. and $\$ 0.04 / \mathrm{bu}$. lower than the harvest price in Illinois and Kansas, respectively. In contrast, wheat prices (after storage costs) during the last five months of the post-harvest period, January through May, are, on average, $\$ 0.20 / \mathrm{bu}$. and $\$ 0.24 /$ bu. lower than the harvest price in Illinois and Kansas, respectively. These differences from the harvest price traditionally are attributed to convenience yields cash prices (Working 1949).

The price patterns in Figure 2 indicate that the greater the weight placed on post-harvest prices during the last five months of the marketing window, the lower will be the average price of the market benchmark. For this reason, the ordering of the average prices for the market benchmarks tends to be: 12-month lowest, 20-month, 24-month, and harvest highest. This explains why marketing performance of farmers in this study is best versus the 12-month benchmark and worst versus the harvest price benchmark.

The same ordering is present in the market benchmarks computed by Anderson and Brorsen (2005) for wheat in Oklahoma and Hagedorn et al. (2005) for corn and soybeans in Illinois. Hence, marketing performance of farmers in these two studies, like the present one, is best versus the 12-month benchmark and worst versus the harvest price benchmark. Klumpp, Brorsen, and Anderson argue that the 12-month benchmark may not be a good choice for evaluating wheat marketing performance in Oklahoma since Oklahoma is relatively close to the Gulf, and therefore, producers have in incentive to sell early in the marketing year. They go on to suggest that a 12-month benchmark may work reasonably well for corn in Illinois since it is near the center of U.S. corn production. Since the same ordering of market benchmarks and conclusions about farmer marketing performance are found in Illinois for corn, soybeans, and wheat as in Oklahoma and Kansas for wheat, a spatially-based argument is unlikely to provide a general explanation. This is reinforced by noting the similar levels of average harvest prices for Illinois and Kansas in this study (Table 1) and the similar seasonal patterns of prices across the two states (Figure 2).

The average difference results also show that the marketing performance of wheat farmers is slightly better in Illinois than Kansas. This can be explained by the marketing patterns of farmer in each state in combination with the price patterns discussed above. Figure 3 presents the average USDA marketing weights for wheat farmers in Illinois and Kansas over 1982-2004. Note that wheat farmers in Kansas, on average, market $24 \%$ of their wheat crop after December (post-harvest), while farmers in Illinois market only 14\%. The greater weight on sales after December and marginally higher penalty for sales during the last five months of the post-harvest period in Kansas (\$0.24/bu. vs. \$0.20/bu.) explains the tendency for Kansas wheat farmers to slightly underperform their counterparts in Illinois.

Finally, to test whether marketing performance changes over time, linear trend regressions are estimated for each time-series of differences between the farmer and market benchmarks in Illinois and Kansas. An example for each state is shown in Figure 4. Note that the slopes of the trend lines are very close to zero for both Illinois and Kansas. Not surprisingly, the explanatory 
power of the two regressions is close to zero and the trend coefficients are statistically insignificant. Similar results are found in all other cases; in particular, none of the trend coefficients are statistically significant. ${ }^{8}$ Hence, there is no evidence that aggregate marketing performance of Illinois and Kansas wheat producers changed over the sample period.

\section{Conclusions}

The marketing performance of crop farmers has important implications for the overall economic performance of the farm sector and Extension programming. Previous research provides conflicting results whether crop farmers outperform or underperform the market. The purpose of this paper is to investigate the marketing performance of wheat farmers in Illinois and Kansas over 1982-2004. The use of two states, multiple market benchmarks, and a relatively long sample period provides important evidence on the sensitivity of performance results to geographic area, benchmark, and time period.

The results show that farmer benchmark prices for wheat in Illinois and Kansas fall in the middle-third of the price range about half to three-quarters of the time. Consistent with previous studies, this refutes the contention that Illinois and Kansas wheat farmers routinely market the bulk of their wheat crop in the bottom portion of the price range. Tests of the average difference between farmer and market benchmark prices are sensitive to the market benchmark considered. Marketing performance of wheat farmers in Illinois and Kansas is about equal to the market if 24- or 20-month market benchmarks are used, is slightly above the market if a 12-month price benchmark is used, and is significantly less than the market if the harvest benchmark is used. Underperformance versus the harvest price benchmark averages $\$ 0.06 / \mathrm{bu}$. in Illinois and $\$ 0.10 /$ bu. in Kansas. While Illinois producers performed slightly better than their counterparts in Kansas, notable differences in performance across these two geographic areas is not observed. Finally, there is no evidence that aggregate marketing performance of Illinois and Kansas wheat producers changed over the sample period.

The sensitivity of marketing performance to the market benchmark considered is explained by the seasonal pattern of prices. There is a sharp drop in storage cost-adjusted prices during the last five months of the marketing window, and hence, the greater the weight placed on postharvest prices during this period, the lower will be the average price of the market benchmark. For this reason, the ordering of the average prices for the market benchmarks tends to be: 12month lowest, 20-month, 24-month, and harvest highest. This explains why marketing performance of farmers in this study is best versus the 12-month benchmark and worst versus the harvest price benchmark.

So, what is the correct answer regarding crop marketing performance of farmers? Technically, the answer depends on the market benchmark considered. From a practical standpoint, none of the under- or over-performance estimates reported in this or previous studies are economically large. Nonetheless, there is a tendency across crops and states for farmers to store too long relative to the average price offered by the market during harvest. Anderson and Brorsen (2005) suggest this may be due to a psychological bias on the part of crop farmers to hold losing positions too long. It is also possible that crop farmers simply do not fully understand seasonal price patterns. There is a large amount of variation in prices from year-to-year and this may obscure longer-term seasonal patterns. At a minimum, the results indicate crop farmers could 
benefit by a better understanding of seasonal price patterns and the attendant impacts on marketing performance 


\section{References}

Allen, P. G. 1994. "Economic Forecasting in Agriculture.” International Journal of Forecasting 10:81-135.

Anderson, K.B., and B.W. Brorsen. 2005. "Marketing Performance of Oklahoma Farmers.” American Journal of Agricultural Economics 87:1265-1270.

Benirschka, M., and J. K. Binkley. 1995. "Optimal Storage and Marketing Over Space and Time." American Journal of Agricultural Economics 77:512-524.

Dietz, S.N. 2004. The Marketing Performance of Wheat Farmers in Illinois and Kansas. M.S. Thesis, Department of Agricultural and Consumer Economics, University of Illinois at Urbana-Champaign.

Fama, E. 1970. "Efficient Capital Markets: A Review of Theory and Empirical Work." Journal of Finance 25:383-417.

Hagedorn, L.A., S.H. Irwin, D.L. Good, and E.V. Colino. 2005. "Does the Performance of Illinois Corn and Soybean Farmers Lag the Market?” American Journal of Agricultural Economics 87:1271-1279.

Irwin, Scott H., Darrel L. Good and Joao Martines-Filho. 2006. “The Performance of Market Advisory Services in Corn and Soybeans.” American Journal of Agricultural Economics 88:162-181.

Jirik, M.A., D.L Good, S.H. Irwin, T.E. Jackson, and J. Martines-Filho. 2000. "The 1995 Through 1998 Pricing Performance of Market Advisory Services for Wheat.” AgMAS Project Research Report 2000-02, Department of Agricultural and Consumer Economics, University of Illinois at Urbana-Champaign. [http://www.farmdoc.uiuc.edu/agmas/reports/2000-02/agmas_2000-02.pdf]

Kansas Agricultural Statistics Service (KASS). 2004. "Kansas Wheat Quality 2004.” [http://www.nass.usda.gov/ks/wq/2004/wq04pdf.pdf]

Kansas Farm Management Association (KFMA). 2004. "Profit Center Analysis: 5-Year Average and 2004 Non-Irrigated Wheat, State Average.”

[http://www.agmanager.info/farmmgt/income/enterprise/2004/EnterpriseNonIrrigatedCro ps/StateNonIrrigatedWheat.pdf]

Klumpp, J.M., B.W. Brorsen, and K.B. Anderson. 2007. "Determining the Returns to Storage: Does Data Aggregation Matter?” Journal of Agricultural and Applied Economics 39:571579.

Kunze, J. 1990. “The Bureau of Agricultural Economics’ Outlook Program in the 1920s as Pedagogical Device.” Agricultural History 64:252-261. 
Martines-Filho, J., D.L. Good, and S.H. Irwin. 2001. “1999 Pricing Performance of Market Advisory Services for Wheat.” AgMAS Project Research Report 2001-03, Department of Agricultural and Consumer Economics, University of Illinois at Urbana-Champaign. [http://www.farmdoc.uiuc.edu/agmas/reports/2001-03/agmas_2001-03.pdf]

National Agricultural Statistics Service (NASS), U.S. Department of Agriculture. 2002. “2002 Prices Received Survey: Interviewer’s Manual.”

National Agricultural Statistics Service (NASS), U.S. Department of Agriculture. 2003. "Corn, Soybeans and Wheat Sold Through Marketing Contracts: 2001 Summary.” Sp Cr 10 (03). [http://usda.mannlib.cornell.edu/reports/nassr/field/pgs-bb/special-reports/]

Working, H. 1949. "The Theory of Price of Storage." American Economic Review 39:1254-1262.

Wright, B. D., and J. C. Williams. 1989. "A Theory of Negative Prices for Storage." Journal of Futures Markets 9:1-13. 


\section{Endnotes}

${ }^{1}$ The survey collects data on the quantity of grain purchased from farmers by crop and the gross value of sales made during the previous month. Quantities are reported at the standard weight of the crop (60 pounds per bushel for wheat). The gross value reported by purchasers includes quality discounts and premiums. Quality adjustment discounts can be taken due to excess moisture levels and grade factors such as protein, test weight, broken kernels, and foreign material. Gross value estimates do not reflect deductions for storage, grading, etc. (NASS 2002). Grain purchases are reported in the month when the buyer takes delivery of the grain. Transactions involving spot cash sales, forward contracts, basis contracts, minimum price contracts, and hedge-to-arrive contracts are all reported in the month of delivery. The only exceptions to this reporting rule are deferred payment sales and delayed pricing contracts. Both the quantity and gross value of these sales are recorded in the month payment is received (NASS 2002).

${ }^{2}$ Marketing loan benefits consist of either loan deficiency payments (LDPs) or marketing loan gains (MLGs).

${ }^{3}$ This assumption may not apply for the 1986 and 1987 crop years when the payment-in-kind (PIK) program was in operation. The data needed to adjust for the PIK program activities of Illinois and Kansas wheat farmers in these years are not available.

${ }^{4}$ Spot cash market prices are available for the entire post-harvest period. Pre-harvest forward contract prices generally are available starting about January $1^{\text {st }}$ of the calendar year of harvest in Illinois and August $1^{\text {st }}$ of the calendar year before harvest in Kansas. Pre-harvest forward prices before this date are computed using a forward basis estimate and settlement prices of the Chicago Board of Trade (CBOT) July wheat futures contracts in Illinois and the Kansas City Board of Trade (KCBOT) wheat futures contracts in Kansas. Since the estimation of pre-harvest forward cash bids is dependant upon the availability of futures data, 24-month benchmarks for Kansas in the 1982, 1983, 1985, 1988, and 1991 crop years are slightly abbreviated: they begin in the first month for which complete price data exists.

${ }^{5}$ More specifically, wheat yields for the West Southwest CRD in Illinois and Southwest CRD in Kansas are used.

${ }^{6}$ Note that this also holds when comparing coefficients of variation, which normalize for the differences in average price and revenue levels across the two states.

${ }^{7}$ Jarque-Bera tests do not reject normality of the differences in any of the eight cases for Illinois and but normality is rejected for five of eight cases for Kansas. Since there is evidence of nonnormality in the differences for Kansas, a van der Waerden non-parametric test of median equivalence also is applied. Hypothesis test conclusions are the same. These results are available from the authors upon request.

8 These results are available from the authors upon request. 
Table 1. Farmer and Market Benchmark Descriptive Statistics for Wheat in Illinois and Kansas, 1982-2004 Crop Years

\begin{tabular}{|c|c|c|c|c|c|}
\hline \multirow[b]{2}{*}{ State/Statistic } & \multirow[b]{2}{*}{$\begin{array}{c}\text { Farmer } \\
\text { Benchmark }\end{array}$} & \multicolumn{4}{|c|}{ Market Benchmarks } \\
\hline & & $\begin{array}{c}\text { 24-Month } \\
\text { Marketing } \\
\text { Window }\end{array}$ & $\begin{array}{l}\text { 20-Month } \\
\text { Marketing } \\
\text { Window }\end{array}$ & $\begin{array}{c}\text { 12-Month } \\
\text { Marketing } \\
\text { Window }\end{array}$ & $\begin{array}{c}\text { Harvest } \\
\text { Price }\end{array}$ \\
\hline \multicolumn{6}{|l|}{ Illinois - Price } \\
\hline Average (\$/bu.) & 3.02 & 3.03 & 3.01 & 2.96 & 3.08 \\
\hline Standard Deviation (\$/bu.) & 0.50 & 0.37 & 0.41 & 0.50 & 0.52 \\
\hline Minimum (\$/bu.) & 2.39 & 2.39 & 2.43 & 2.32 & 2.38 \\
\hline Maximum (\$/bu.) & 4.22 & 3.94 & 4.06 & 4.29 & 4.61 \\
\hline Range (\$/bu.) & 1.82 & 1.56 & 1.63 & 1.98 & 2.22 \\
\hline Cofficient of Variation (\%) & 16.5 & 12.1 & 13.7 & 17.0 & 16.8 \\
\hline \multicolumn{6}{|l|}{ Kansas - Price } \\
\hline Average (\$/bu.) & 2.93 & 2.91 & 2.92 & 2.90 & 3.03 \\
\hline Standard Deviation (\$/bu.) & 0.59 & 0.42 & 0.48 & 0.61 & 0.66 \\
\hline Minimum (\$/bu.) & 2.00 & 2.11 & 2.11 & 1.99 & 2.12 \\
\hline Maximum (\$/bu.) & 4.42 & 4.09 & 4.29 & 4.65 & 5.06 \\
\hline Range (\$/bu.) & 2.42 & 1.98 & 2.17 & 2.66 & 2.94 \\
\hline Cofficient of Variation (\%) & 20.2 & 14.5 & 16.3 & 21.0 & 21.8 \\
\hline \multicolumn{6}{|l|}{ Illinois - Revenue } \\
\hline Average (\$/ac.) & 160 & 160 & 160 & 157 & 163 \\
\hline Standard Deviation (\$/ac.) & 35 & 31 & 33 & 36 & 33 \\
\hline Minimum (\$/ac.) & 93 & 94 & 93 & 101 & 92 \\
\hline Maximum (\$/ac.) & 231 & 218 & 222 & 220 & 237 \\
\hline Range (\$/ac.) & 138 & 124 & 129 & 119 & 145 \\
\hline Cofficient of Variation (\%) & 21.6 & 19.3 & 20.4 & 22.8 & 20.6 \\
\hline \multicolumn{6}{|l|}{ Kansas - Revenue } \\
\hline Average (\$/ac.) & 107 & 108 & 108 & 106 & 111 \\
\hline Standard Deviation (\$/ac.) & 16 & 20 & 18 & 15 & 19 \\
\hline Minimum (\$/ac.) & 73 & 71 & 77 & 73 & 78 \\
\hline Maximum (\$/ac.) & 139 & 142 & 139 & 135 & 142 \\
\hline Range (\$/ac.) & 65 & 70 & 62 & 62 & 64 \\
\hline Cofficient of Variation (\%) & 14.8 & 18.2 & 16.6 & 14.6 & 16.8 \\
\hline
\end{tabular}

Notes: The marketing window for farmer benchmarks is the 12-month period starting in June of the calendar year of harvest and ending in May of the calendar year after harvest. The marketing window for the 24-month market benchmark starts in June of the calendar year previous to harvest and ends in May of the calendar year after harvest. The marketing window for the 20-month market benchmark starts in October of the calendar year of harvest and ends in May of the calendar year after harvest. The marketing window for the 12-month market benchmark starts in June of the calendar year of harvest and ends in May of the calendar year after harvest. Post-harvest prices for the farmer and market benchmarks are adjusted for commercial physical storage costs and interest opportunity costs; therefore, all benchmark prices are stated on a harvest equivalent basis. Farmer benchmark prices include effective LDP/MLG payments during the 1998-2004 crop years (LDP: loan deficiency payment; MLG: marketing loan gain). Market benchmark prices include LDP/MLG payments for the 1998-2004 crop years. 
Table 2. Frequency of Farmer Benchmark Prices Falling in the Top-, Middle- and Bottom-Third of Crop Year Price Ranges for Wheat in Illinois and Kansas, 1982-2004 Crop Years

\begin{tabular}{lccccc}
\hline \multirow{2}{*}{ State } & Price Range & \multicolumn{2}{c}{ Marketing Window for Price Distribution } & \\
\cline { 3 - 4 } Illinois & & 24-Month & 20-Month & 12-Month & Average \\
\hline & & & & & \\
& Top Third & $17 \%$ & -- -frequency--- & & \\
& Middle Third & $65 \%$ & $74 \%$ & $52 \%$ & $64 \%$ \\
Kansas & Bottom Third & $17 \%$ & $9 \%$ & $13 \%$ & $13 \%$ \\
& & & & & \\
& Top Third & $9 \%$ & $9 \%$ & $17 \%$ & $12 \%$ \\
& Middle Third & $61 \%$ & $70 \%$ & $61 \%$ & $64 \%$ \\
\hline
\end{tabular}

Notes: The 24-month marketing window starts in June of the calendar year previous to harvest and ends in May of the calendar year after harvest. The 20-month marketing windoe starts in October of the calendar year of harvest and ends in May of the calendar year after harvest. The 12-month marketing window starts in June of the calendar year of harv $\epsilon$ and ends in May of the calendar year after harvest. Post-harvest prices for the farmer benchmarks and price distributions are adjusted for interest opportunity costs and commercial physical storage costs. Neither the farmer benchmarks nor the price ranges include LDP/MLG payments during the 1998-2004 crop years (LDP: loan deficiency payment; MLG: marketing loan gain). 
Table 3. Average Difference Between Farmer and Market Benchmarks for Wheat in Illinois and Kansas, 1982-2004 Crop Years

\begin{tabular}{lcccc}
\hline & \multicolumn{4}{c}{ Average Difference between Farmer and Market Benchmark } \\
\cline { 2 - 4 } State & \multicolumn{5}{c}{ 24-Month } & 20-Month & 12-Month & Harvest Price \\
Market Benchmark Market Benchmark Market Benchmark Market Benchmark
\end{tabular}

Notes: Post-harvest prices for farmer and market benchmarks are adjusted for interest opportunity costs an commercial physical storage costs, therefore, all benchmark prices are stated on a harvest equivalent basis. Farmer benchmark prices include effective LDP/MLG payments during the 1998-2004 crop years (LDP: loan deficiency payment; MLG: marketing loan gain). Market benchmark prices include LDP/MLG payment for the 1998-2004 crop years. Figures in parentheses are t-statistics. One, two, and three stars indicate significance at the ten, five, and one percent levels, respectively. 


\section{Panel A. Illinois}

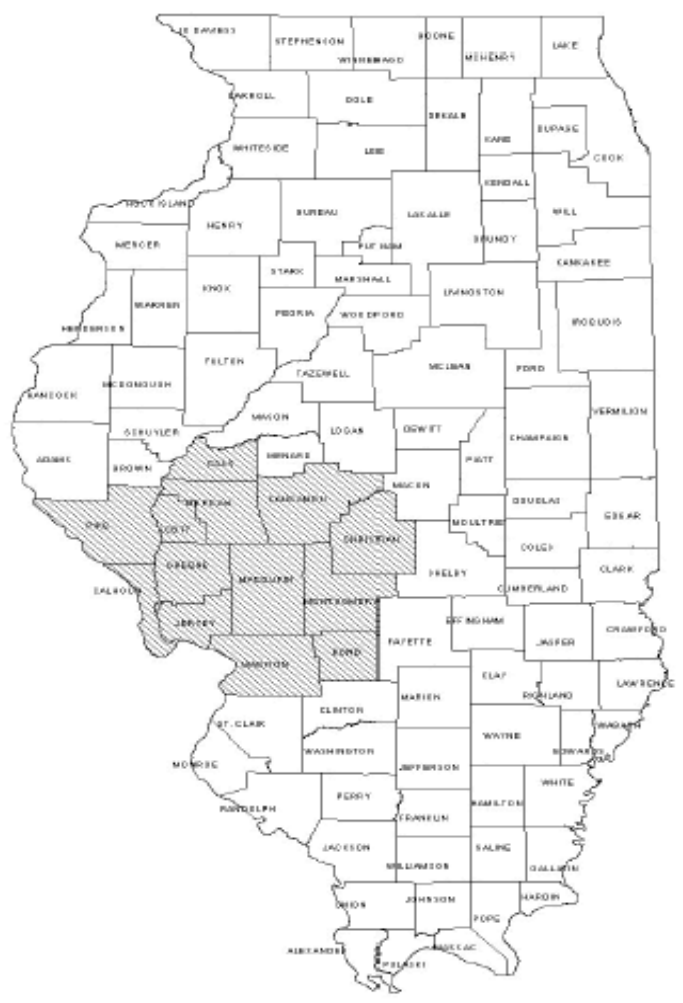

Panel B. Kansas

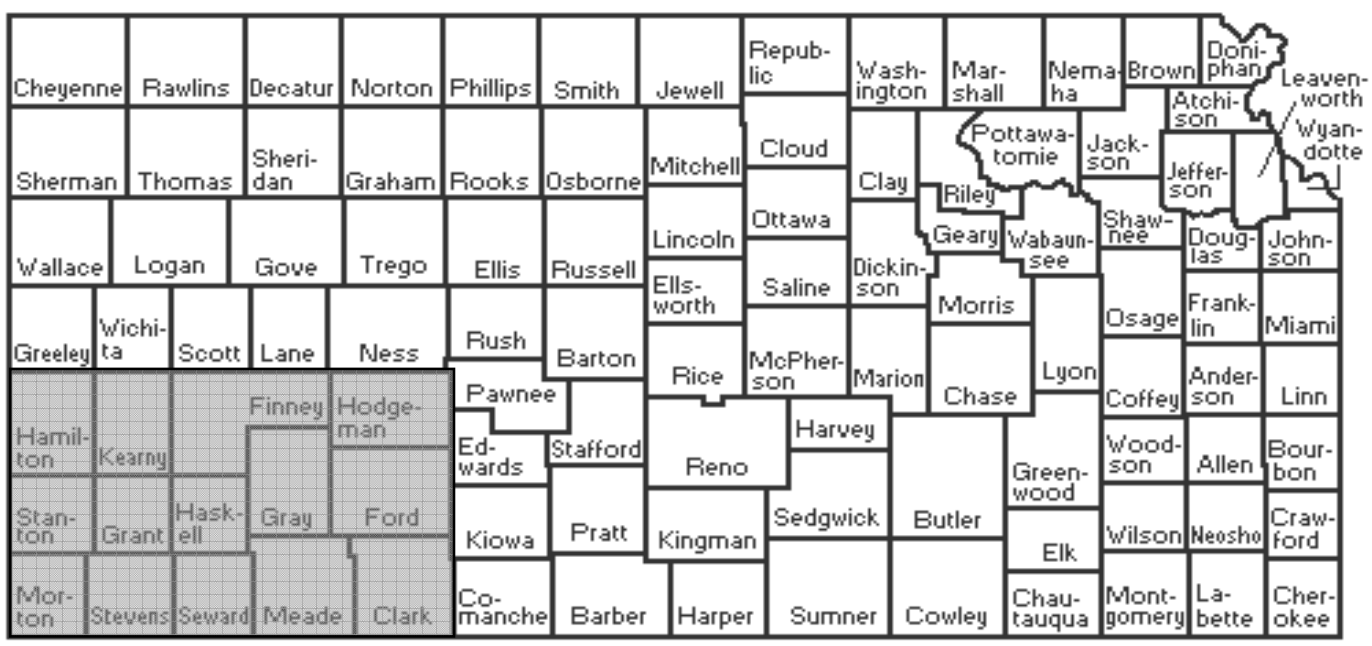

Figure 1. Geographic Areas (Crop Reporting Districts) Used to Measure Marketing Performance of Wheat Farmers in Illinois and Kansas 
Panel A. Illinois

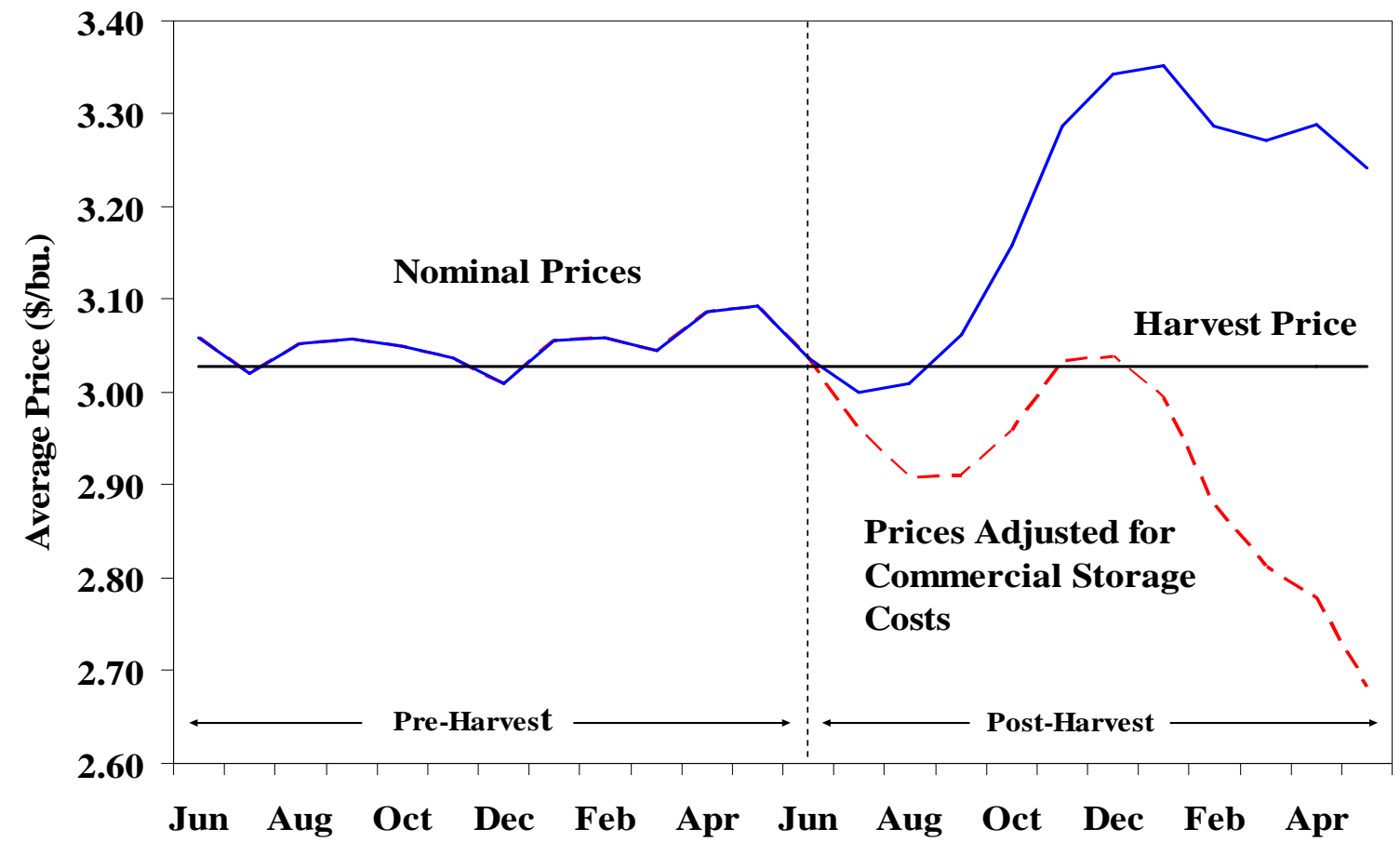

Panel B. Kansas

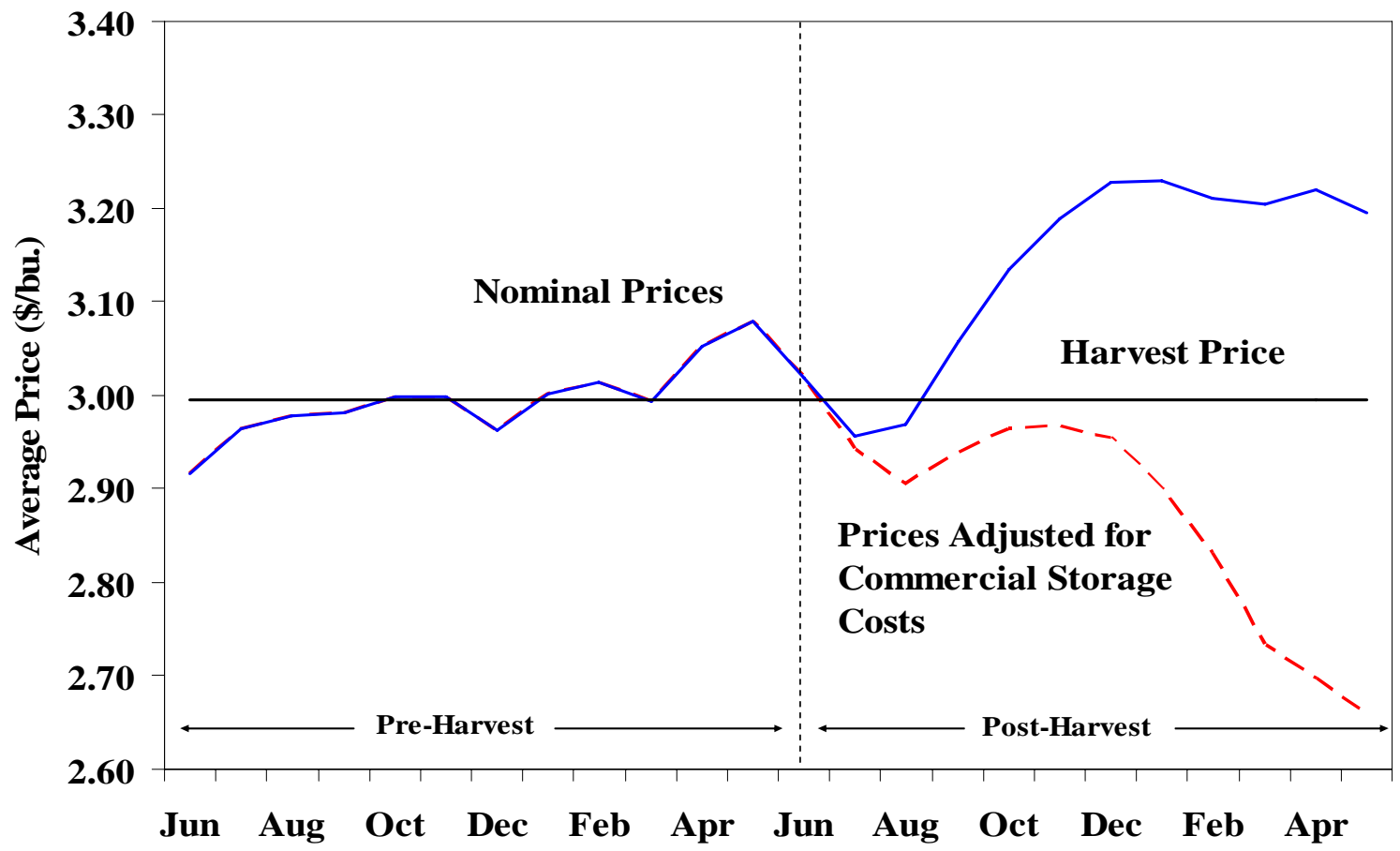

Figure 2. Average Monthly Wheat Prices in Southwestern Illinois and Southwestern Kansas, 1982-2004 


\section{Panel A. Illinois}

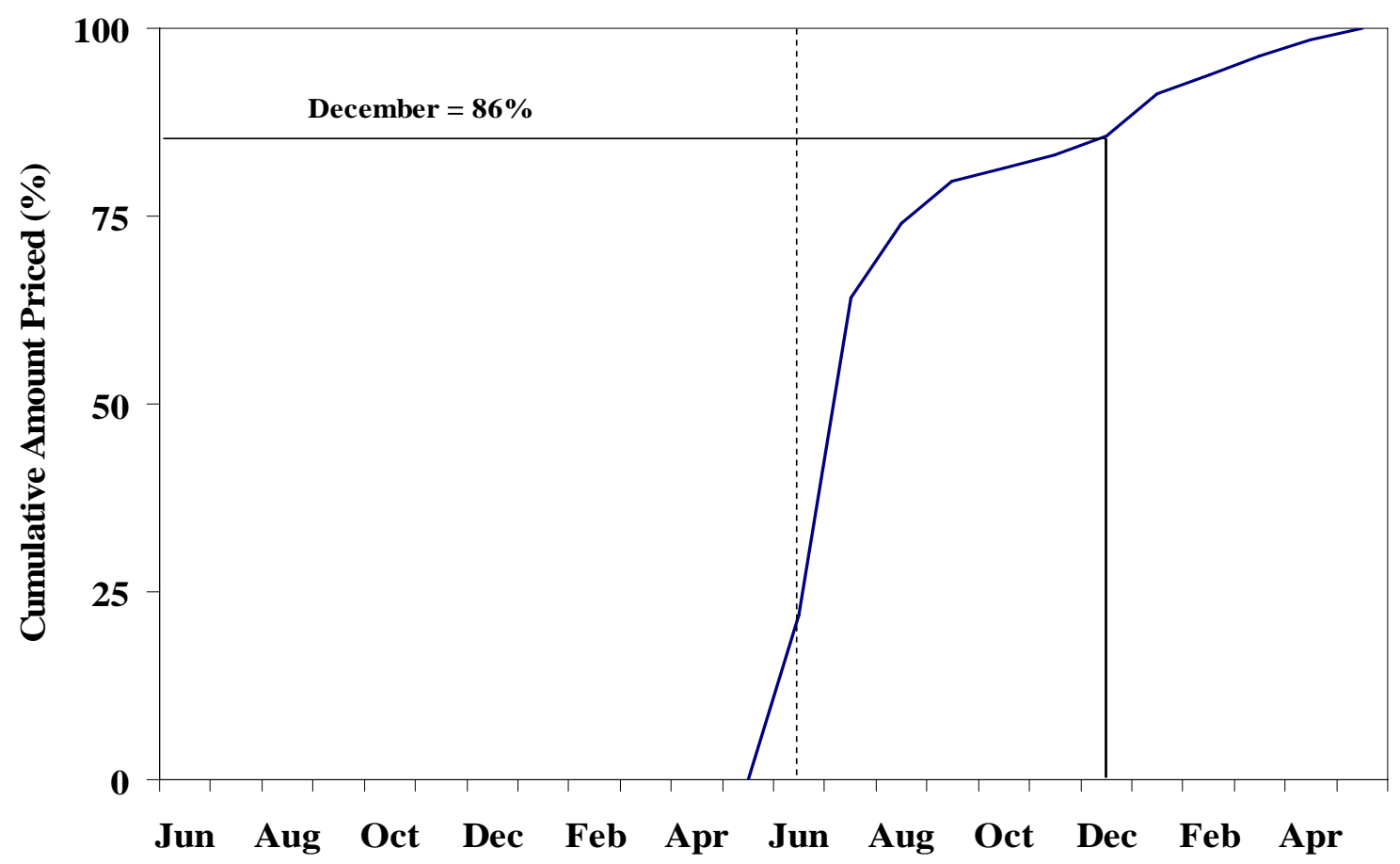

Panel B. Kansas

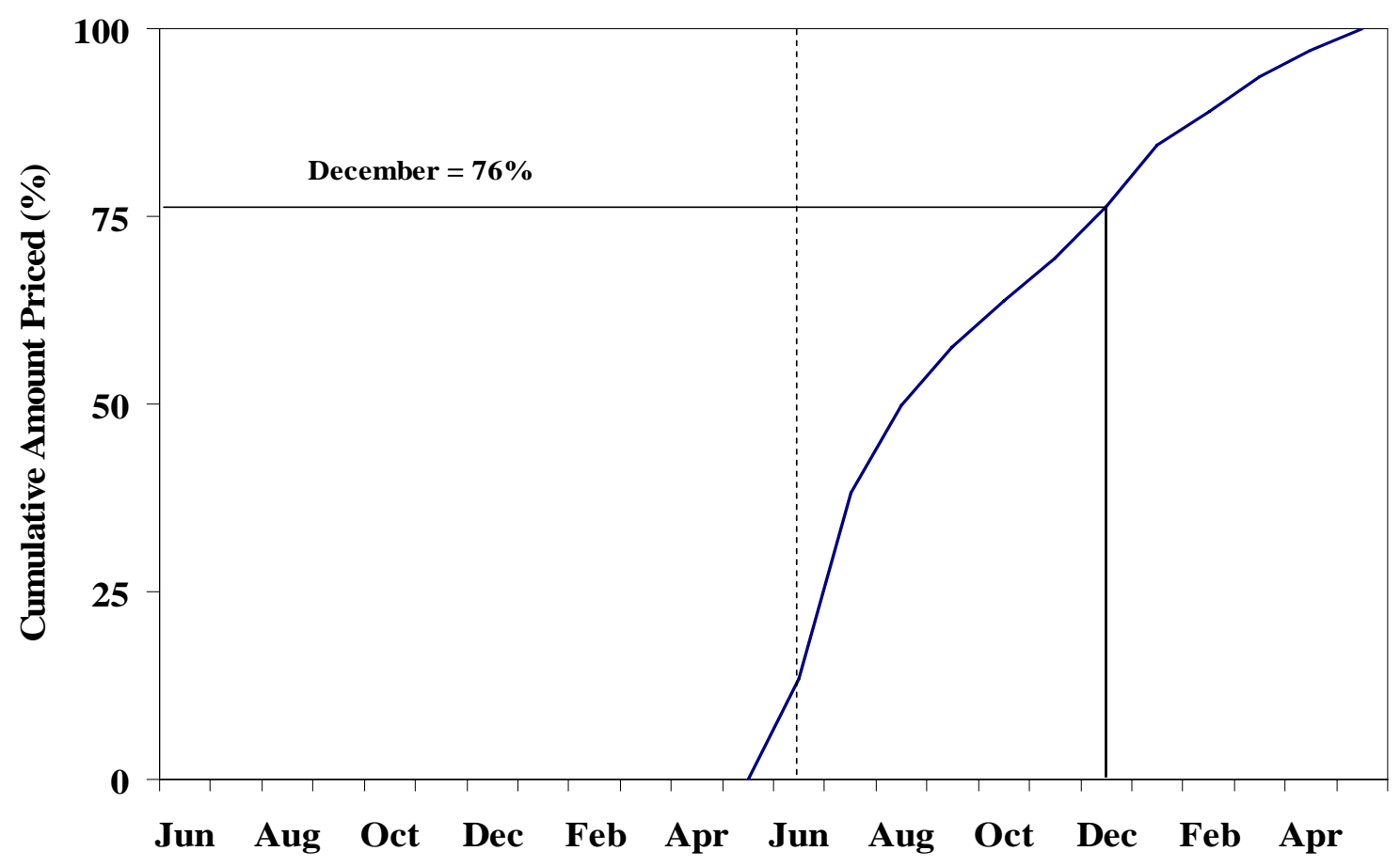

Figure 3. Average USDA Marketing Weights (Cumulative) for Wheat Farmers in Illinois and Kansas, 1982-2004 
Panel A. Illinois

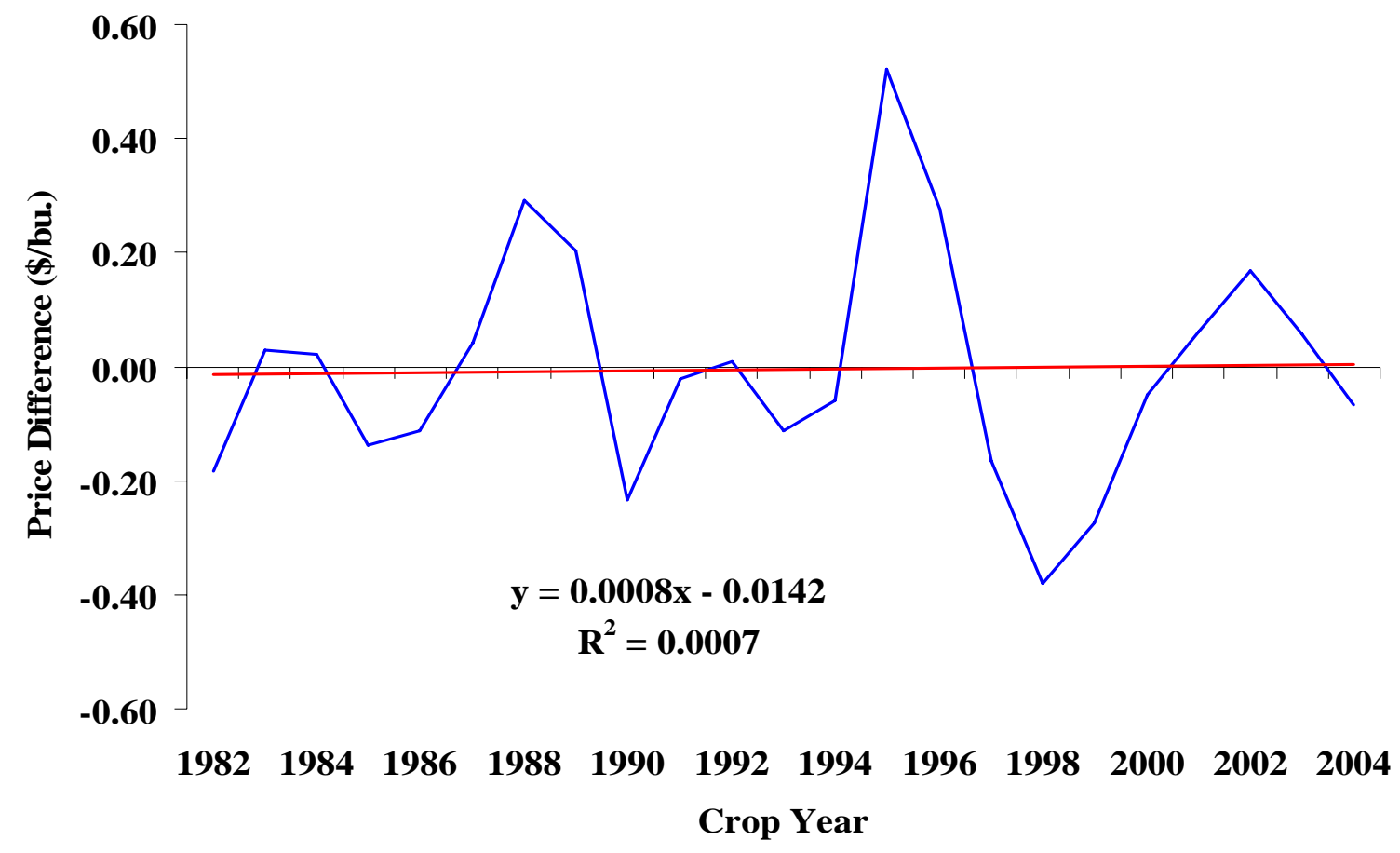

Panel B. Kansas

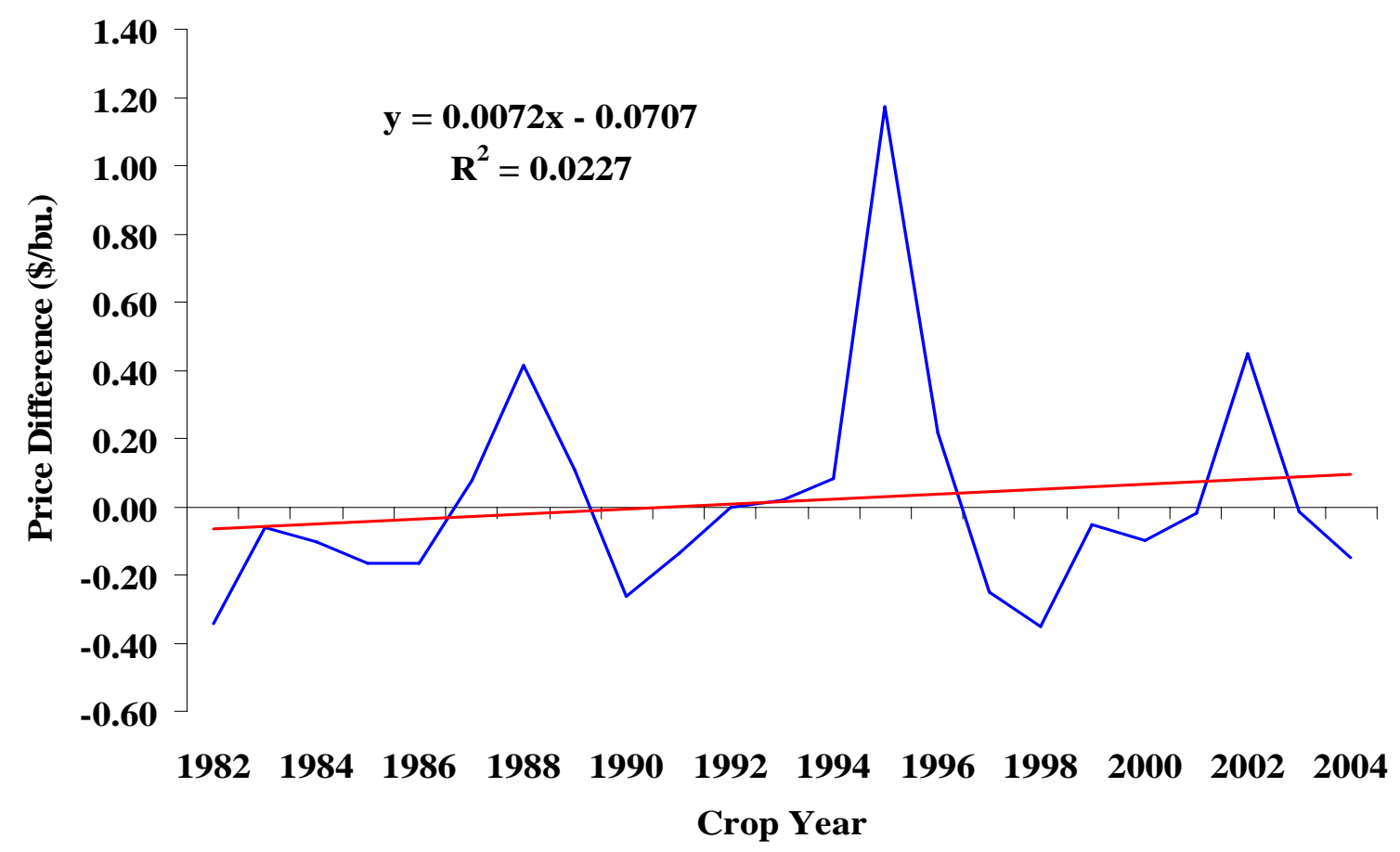

Figure 4. Difference Between Farmer and 24-Month Market Benchmarks for Wheat in Illinois and Kansas, 1982-2004 